\title{
DELIVERY SYSTEM DESIGN FOR RISK MANAGEMENT IN SHARING-BASED PRODUCT SERVICE SYSTEMS: A CUSTOMER- ORIENTED APPROACH SERVICE
}

\author{
Simon HAZÉE \\ Université catholique de Louvain, LouRIM, CCMS, Belgium \\ simon.hazee@uclouvain.be \\ (Corresponding author) \\ Yves VAN VAERENBERGH \\ KU Leuven, Belgium \\ Cécile DELCOURT \\ HEC Liège - Management School of the University of Liège, Belgium \\ Sertan KABADAYI \\ Gabelli School of Business - Fordham University, USA
}

This paper is an author post-print version of a paper forthcoming in the International Journal of Operations \& Production Management

DOI: 10.1108/IJOPM-08-2019-0581 


\section{Service delivery system design for risk management in sharing-based product service systems: A customer-oriented approach}

\section{Structured abstract}

Purpose: Organizations increasingly develop and offer sharing services enabled by means of product-service systems (PSS). However, organizations offering sharing-based PSS face a unique set of design challenges and operational risks. This paper provides researchers and practitioners with customer-based insights into service delivery system design and risk management for sharing-based PSS operational success.

Design/methodology/approach: This qualitative study combines in-depth interviews with supplementary, multidisciplinary literature and secondary firm data. In total, the authors conducted 56 semi-structured interviews with diverse customers across different B2C PSS settings.

Findings: First, the authors develop an integrative conceptual framework that reveals what structural and infrastructural design choices customer expect organizations to make for mitigating risks and enhancing customer-perceived value in the sharing economy. These design choices may influence customers' trust and control perceptions in all actors involved in the service delivery system. Second, the results suggest that sharing value proposition, customerperceived level of consequentiality, and level of customer-supplied resources are contingency factors that need to be considered when making design decisions for risk management in the sharing economy.

Originality/value: This study extends Sampson's Unified Service Theory by proposing that, with sharing-based PSS, production flows from customers to customers. This situation creates unique challenges for operations management. This paper extends current understanding of the role, characteristics, and contingencies of service delivery system design for risk management 
in the sharing economy. In doing so, the authors challenge common wisdom and suggest understanding both the organizational and customers' individual contexts is critical for (contingency) theory and practice.

Keywords: Product-Service Systems (PSS), Servitization, Risk management, Service delivery system design, Sharing Economy, Trust.

Paper type: Research paper. 


\section{Introduction}

Organizations increasingly embrace a servitization strategy to remain competitive, develop close customer relationships, and generate new revenue streams (Baines and Lightfoot, 2014). A promising servitization strategy is to develop and offer sharing services, which are typically enabled and performed by means of product-service systems (PSS) (Akbar and Hoffmann, 2020; Annarelli et al., 2016). In such sharing-based PSS, organizations offer customers access to assets that would otherwise have remained under-utilized, as is the case with traditional ownership models (Wirtz et al., 2019). For example, the car manufacturer BMW developed the car-sharing program "DriveNow", which allows customers to increase utilization of BMW cars with spare capacity. PriceWaterhouseCoopers (2014) estimates that the global revenues of the sharing economy could reach $\$ 335$ billion by 2025 , against $\$ 15$ billion today. Authors even argue "we just may be entering the post-ownership economy" (Belk, 2014, p. 1599), where organizations would no longer rely on business models centered around product ownership, but rather move towards PSS that provide customers with access to various assets and resources (Rifkin, 2000).

As research on servitization shows, the transition from a product- to a more serviceoriented business model creates a set of significant operational challenges and risks for organizations, which urgently and carefully need to be addressed for the service success (e.g., Benedettini et al., 2015; Erkoyuncu et al., 2013; Neely, 2009; Sakao et al., 2013; Ulaga and Reinartz, 2011). PSS-based business models that enable the sharing economy introduce even more challenges and risks (Damali et al., 2020). Among others, organizations risk operational issues due to the highly complex delivery systems (Victorino et al., 2018) as well as to the heterogeneity of customers (Field et al., 2018). Sharing economy customers play an enhanced role in the service delivery—without much employee supervision — and depend highly on each other's cooperation for successful delivery (Hazée et al., 2017). Building upon and extending 
the Unified Service Theory (Sampson, 2000; Sampson and Froehle, 2006), this research argues that sharing-based PSS are unique in the sense that they imply triadic 'organization-customerother customer' relationships, breaking down the applicability of traditional operations, human resources, and risk management practices that are inherent to employee-based service delivery systems (Andreassen et al., 2018). According to Field et al. (2018), the sharing economy would even represent a "paradigm shift in service business models and delivery system structure, which warrants new service operations strategies" (p. 73).

This study connects with the recent call for further research on the operational implications of the sharing economy (Victorino et al., 2018). Echoing previous discussion in literature on the importance of considering the human side in operations management (e.g., Johnstone et al., 2009; Pawar et al., 2009; Smith et al., 2014), this study takes a customeroriented approach and considers customers as 'design engineers' (Sampson and Spring, 2012). In particular, the present research explores how customers expect sharing-based PSS to be designed for risk management and effective operation. Beyond providing a customer-based understanding of the characteristics as well as contingencies of service delivery systems in unique sharing-based PSS, this study also looks to address Field et al.'s (2018) challenge around the design and management of sharing services to influence customers' sense of trust and control perceptions. This paper specifically contributes to the operations management literature by addressing the following two main research questions:

$R Q 1$. What service delivery design choices do customers expect organizations to make in order to manage risks for sharing-based PSS operation?

$R Q 2$. What are the contingency factors upon which risk management approaches (and related customer-based design choices) depend?

The remainder of this paper is structured as follows. First, the relevant literature is reviewed and discussed to highlight the gaps in current knowledge that support the research questions. 
Second, the paper explains the methodological choices, data collection and analysis. Third, the study's findings are presented and discussed against prior research, leading to the formulation of some key propositions. Fourth, this paper discusses the implications for both research and practice, before identifying fruitful avenues for future research.

\section{Conceptual background}

\subsection{PSS and the sharing economy}

A PSS is defined as a marketable mix of products and services capable of jointly fulfilling final customers' needs through an innovative design of the value delivery system (Goedkoop et al., 1999; Tukker, 2004). PSS offerings can vary in their business model and value proposition, ranging from product- to use- and result-oriented PSS (for an overview, see Tukker, 2004). The strength of a PSS lies in its inherent focus on the final demand or function that needs to be fulfilled (Tukker and Tischner, 2006). Interestingly, PSS would not only enable organizations to enhance their competitiveness through revenue generation and costs savings, but also foster sustainability through the reduction of material resources consumption and alternative scenarios of product usage (Mont, 2002).

Recently, studies started to investigate the intersection between PSS and the sharing economy (e.g., Akbar and Hoffmann, 2020). The sharing economy represents an innovative way to fulfill customers' needs by focusing on product functions and end results, thereby moving away from traditional product and ownership concepts (Annarelli et al., 2016). In particular, sharing-based PSS provide customers with access to products that remain in an organization's ownership (e.g., bike- and car-sharing programs) or make privately-owned, capacity-constrained goods available to other people within a community (e.g., peer-to-peer accommodation) in exchange for access fees (Piscicelli et al., 2015; Wirtz et al., 2019). 
According to Botsman and Rogers (2011), use-oriented PSS would be the most popular type of PSS used to enable and perform B2C sharing services.

Developing and offering service-oriented business solutions like sharing-based PSS comes with numerous specific operational challenges and risks for organizations. According to the Unified Service Theory (Sampson, 2000), all managerial issues that are unique to services are founded in the "customer-as-resource-supplier" distinction. A significant distinguishing characteristic of services is indeed that they involve bidirectional supply chain relationships, which require customers to act as suppliers and provide organizations with resources before they are able to perform service processes and meet customers' needs (Sampson and Froehle, 2006). This distinction implies that customers may assume expanded roles in service supply chains compared with traditional supply chains, ranging from component supplier to production manager and design engineer (Sampson and Spring, 2012).

In line with the Unified Service Theory, customers in the sharing economy are active coproducers who provide significant inputs into the production process (Field et al., 2018), thereby introducing high uncertainty and variation in the service delivery and making high demands on the service delivery system (Zomerdijk and de Vries, 2007). This research yet argues that sharing-based PSS are distinct from traditional (service) supply chains, as conceptualized in Sampson's work. In a sharing-based PSS, customers highly depend on each other's cooperation for successful delivery, therefore making it important to carefully design the service in order to influence intended customer behavior as well as customers' sense of trust and control perceptions (Field et al., 2018; Perren and Kozinets, 2018). For instance, in the case of car-sharing, a car returned to its parking space late by one user may spoil the next user's experience with the service, erode trust, and ultimately destroy customer-perceived value (Frei, 2006). In a similar vein, in the case of accommodation sharing, customers who act as peer service providers face the risk that other customers might damage their personal assets 
(e.g., apartment) or misbehave in general (Andreassen et al., 2018). Hence, with sharing-based PSS, production not only flows from organizations to customers and from customers to organizations (Sampson and Froehle, 2006), but also from customers to customers who act as suppliers of resources for one another (see Figure 1).

\section{[Insert FIGURE 1 around here]}

These triadic 'organization-customer-other customer' relationships (albeit sometimes indirect, as in the car-sharing example) may create specific operational challenges and risks for organizations. However, at this point, "there has yet to be any coverage from an operationsfocused perspective on this theme [sharing economy]" (Victorino et al., 2018, p. 45). This paper specifically draws on the recent conceptual work of Field et al. (2018), in which important challenges of sharing-based PSS for operations management were introduced. In particular, Field et al. (2018) recognize the heterogeneity of customers as co-producers as a key feature of complexity and source of operational risks for organizations operating in the sharing economy. These authors propose that sharing-based PSS would require specific risk management strategies and service delivery design for effective operation since customers play a front-line role without direct employee intervention (Field et al., 2018).

\subsection{Risk management for PSS operation}

Research on risk management within PSS is considered as an important, emerging research area (e.g., Benedettini et al., 2015; Reim et al., 2016). Risk management is typically defined as a three-step process, including risk identification, implementation of an appropriate risk response strategy, and outcome monitoring (Dorfman, 1998). Organizations may face various operational risks, ranging from technical (e.g., machine breakdown risk) to delivery competence (e.g., complex supply chain) and behavioral risks (e.g., adverse customer behavior) (for an overview, see Reim et al., 2016). 
The complexities and characteristics of B2C sharing-based PSS (e.g., triadic 'organization-customer-other customer' relationships, high heterogeneity of customers who play an enhanced role in the service production and delivery, absence of direct supervision) are likely to create various types of operational risks for organizations (Damali et al., 2020). For instance, Bardhi and Eckhardt (2012) show car-sharing users do not show care towards the cars, but rather abuse them and behave opportunistically. Within sharing-based PSS, opportunistic customer behaviors represent behavioral risks for organizations, as well as technical (car breakdown is more likely) and delivery risks since organizations would not be able to deliver on promise (the shared car being unavailable or soiled). More importantly, such adverse behaviors would not only create operational risks to organizations, but also strategic risks, that is, a lack of market acceptance (Oliva and Kallenberg, 2003). Customers may indeed reject sharing-based PSS because of the lack of trust in other users, whom they regard as opportunistic or misbehaving individuals (Hazée et al., 2017, 2019).

The difficulty of mitigating risks and fostering a sense of trust among customers might explain why numerous organizations fail to achieve the benefits of PSS (Erkoyuncu et al., 2013; Roy and Cheruvu, 2009). Despite this observation, knowledge on how organizations offering PSS solutions can manage risks for effective delivery is still in its infancy. Building upon the risk management literature, Reim et al. (2016) identify four main approaches to manage risks in PSS, namely: avoidance, sharing, retention, and reduction. The former refers to the organization avoiding the possibility that the risk can occur. In the case of a PSS, this would imply only offering a PSS without being responsible for breakdowns, carefully segmenting customers, or simply a lack of PSS offering (e.g., Reim et al., 2016). Risk sharing involves organizations transferring risks and responsibilities to other parties involved in the service delivery system through, for instance, joint ownership (e.g., $\mathrm{Ng}$ et al., 2013), the use of conditional contracts (e.g., Roy and Cheruvu, 2009) or insurance policies (e.g., Reim et al., 
2016). Risk retention occurs when organizations accept the taking on of risks and attempt to profit from this situation by pricing the offer accordingly (e.g., Ulaga and Reinartz, 2011). Finally, the risk reduction approach includes tactics aimed at decreasing the frequency or severity of losses. Prior research on PSS identifies risk reduction tactics such as increased resource levels, proactive maintenance, or good data and information handling through the use of sensors (e.g., Isaksson et al., 2009; Reim et al., 2016; Roy and Cheruvu, 2009; Steven, 2012).

Taken together, previous studies consider risk management for PSS as an important future research area and implicitly suggest organizations could mitigate risks through various service design aspects. Interestingly, these strategic design choices could further help sharingbased PSS providers reduce risks by influencing intended customer behavior (Field et al., 2018). Hence, this research argues that increased knowledge about the link between risk management and service delivery system design can help organizations in the context of managing sharing-based PSS operations.

\subsection{Service delivery system design}

The complexities associated with sharing-based PSS require an integration of both product and service operations. Hence, this paper draws upon the service delivery system design literature, which provides considerable arguments that can be brought to bear in developing knowledge on the sharing economy from an operations management perspective. The service strategy triad is a focal concept in operations management; it posits that the service delivery system design addresses "how" the value proposition, or service concept, is delivered to target customers (Roth and Menor, 2003). Previous studies suggest strategic service design choices are typically centered around two key aspects: structure and infrastructure (e.g., Baines et al., 2009; De Regge et al., 2019; Ponsignon et al., 2011). Structural design aspects revolve around the role of 'facility, location, and layout', 'process, technology, and equipment', and 'capacity'. 
Infrastructural design choices mainly refer to the role of 'people' as well as 'policy, procedure, and protocol' (Baines et al., 2009; Baines and Lightfoot, 2014; Roth and Menor, 2003). Overall, this literature identifies the major design issues that need to be considered for effective service operation.

While service system design research is growing, studies empirically addressing the link between design of service systems and risk management remain scarce. Hence, this paper argues that previous studies provide relatively little guidance in specifying the design characteristics that are needed to manage risks for sharing-based PSS operation. Additionally, most operations management studies examining challenges associated with service system design and risk management focus on $\mathrm{B} 2 \mathrm{~B}$ settings with a firm perspective (e.g., De Regge et al., 2019; Reim et al., 2016, 2018). This paper contends that these studies may be too narrow in scope to provide full understanding of how to design and manage sharing-based PSS. Previous findings may indeed not capture what customers actually expect from organizations (Pawar et al., 2009), nor the complexities associated with service design and risk management in B2C market settings, in which organizations must deal with less skilled, more diverse customers (Reim et al., 2015). Given these limitations, an exploratory research was conducted to investigate, from a customer perspective, the key characteristics and contingencies of sharing service delivery design. With this effort, this study addresses recent calls for more research on the operational implications of the sharing economy (e.g., Victorino et al., 2018).

\section{Methodology}

Considering the gaps identified in the literature, this research employs in-depth face-to-face interviews with customers as a method to identify and explore the strategic service design choices that customers expect organizations to make for risk management and effective operation in the sharing economy. Such an exploratory approach is considered appropriate as 
it allows researchers to gain a deeper insight into a complex, underdeveloped research subject (Patton, 2014). In-depth interviews are also deemed particularly suited for the present research objectives as the latter rely on determining and understanding people's (customers) perceptions of a specific phenomenon as a means to detect objective reality (Meredith et al., 1989).

\subsection{Unit of analysis}

As opposed to most previous studies on PSS, this research focuses on customers as the unit of analysis for three main reasons. First, sharing-based PSS require high customer participation in the service production and delivery processes (Field et al., 2018). Hence, it is imperative to understand customers' desired service experience (Beuren et al., 2013) and especially how they want to be treated by PSS providers (Reim et al., 2018). Understanding individual customers' expectations is indeed relevant in the design of complex service solutions (Pawar et al., 2009). Sampson and Spring (2012) even argue customers may have better design ideas than the organization itself, given their experience with the focal organization and other service providers. Second, the observation that many sharing-based PSS fail because they do not generate sufficient customer demand (Hazée et al., 2017) warrants a customer perspective on how organizations can reduce such strategic risks and boost acceptance. Third, examining customers' perceptions of PSS, with a close eye on B2C market settings, is deemed important to achieve the global potential of PSS solutions and the sharing economy (Annarelli et al., 2016).

\subsection{Sampling and sample characteristics}

When sampling, this study sought to maximize diversity among the respondents to achieve a comprehensive view of sharing-based PSS customers' expectations and desires about organizational strategic design choices. Hence, respondents differ in terms of demographic characteristics and adoption state (potential, current, and lost customers). Current and lost customers were included in the sample since customers who adopt an innovation such as a 
sharing-based PSS may return to an evaluation stage and decide to stop using it because of continued uncertainty (Rogers, 1976). Furthermore, sharing-based PSS providing access to four different product categories (car-, bike-, toy-, and tool-sharing programs) were included to (1) extend prior scant research that predominantly focuses on car-sharing (e.g., Firnkorn and Müller, 2012), (2) identify key contingency factors, and (3) enhance generalizability of the findings.

Invitations for the study were displayed via several offline (e.g., university hall) and online channels (e.g., forum dedicated to mobility). This opt-in recruitment process required the interested persons to contact the authors to take part in the study. In addition, participants were recruited through snowball sampling, asking selected respondents to identify other potential participants who shared the characteristics of interest for this study (Patton, 2014). This sampling technique was found appropriate because the organizations' privacy policies make it difficult to access current and lost users of PSS. Such a sampling approach is indeed considered as an effective method to access "hard to reach" populations, information-rich key informants, or critical cases, and is further found particularly useful to find confirming as well as disconfirming cases (Patton, 2014). The sampling process ceased at theoretical saturation, when the information gathered became redundant and no new information appeared in the data (Bowen, 2008). The resulting sample includes 56 persons, consistent with the recommended sample sizes for exploratory research (McCracken, 1988). Respondents, including 30 women, were between the ages 24 and 72, with an average age of 36. The semi-structured interviews include 19 potential, 20 current, and 17 lost customers of sharing-based PSS (see the Appendix for more information about the respondents).

\subsection{Interview guide}

The interview guide consisted of questions related to the informants' expectations and desires regarding organizational sharing service design choices, along with prompts and follow-ups. 
The interview guide included four main parts. In line with best practices (see McCracken, 1988), the first part of the interview began with general questions (e.g., "Please tell me what you think about commercial sharing programs"); the latter were carefully formulated in nontechnical terms and designed to prompt a first-person narrative of the respondent's experience. When a person's experience was linked to a specific sharing-based PSS, the following part of the interview was conducted in relation to this service. In the second part, participants were asked to reflect on the design choices that organizations could or should make for effective operation and risk management. In the third part, participants reflected on access to other types of product categories (i.e., cars, bikes, tools, and toys-sharing programs), the use of different sharing models, and the desired organizational actions that they had previously mentioned. In so doing, the authors could identify the key strategic design choices customers expect organizations to make, regardless of the type of PSS. Finally, interviewees were asked to reflect on how sharing-based PSS providers could influence their sense of trust and control for effective operation.

\subsection{Data analysis and interpretation}

All interviews were audio-recorded and transcribed verbatim, before being coded and analyzed with NVivo. This research used a thematic analytic approach for the data analysis. This is an iterative process of reading, assessing, and identifying emerging themes and categories that organize and describe data in rich detail (Braun and Clarke, 2006). The thematic analysis followed a two-step procedure.

In the first step, the authors coded the transcript, paragraph by paragraph, to identify relevant themes. Theoretical codes identified by prior studies were established prior to starting the coding, then inductive in vivo codes were developed throughout the process to capture themes emerging from the data (Patton, 2014). Like previous studies (e.g., Ulaga and Reinartz, 2011), at this stage, the authors developed a coding plan that sought to (1) list all identified 
desired organizational design choices, (2) provide a label for each construct, (3) specified the properties and relationships between constructs, and (4) offer typical statements to illustrate the meaning and content of every construct. The author team reviewed this plan for internal consistency, leading to some refinement of labels and definitions. Disagreements were resolved through discussion.

In the second step, the authors jointly developed theoretical abstract categories of the identified desired organizational design choices. During the categorization, the authors compared the findings with related multidisciplinary literature to integrate and extend prior knowledge (Strauss and Corbin, 1998). In this integrative process, the following multidisciplinary research streams were included: PSS risk management (e.g., Reim et al., 2016), service delivery system design (e.g., Baines and Lightfoot, 2014), sharing economy (e.g., Perren and Kozinets, 2018) as well as customer (e.g., Singh and Sirdeshmukh, 2000), employee (e.g., Schepers et al., 2012) and alliance management (e.g., Das and Teng, 1998).

\subsection{Validity assessment of the results}

Following established procedures, the authors ensure validity of the findings by applying both data and researcher triangulation. For the data triangulation (for a similar procedure, see for instance Homburg et al., 2017), the authors carefully checked, throughout the analysis, the transferability of the identified concepts across the different types of sharing-based PSS and the types of customers (i.e., potential, current, and lost users) as a means to identify contingencies and ensure generalizability. Moreover, the authors constantly compared the interview data with both supplementary research streams and secondary data (Strauss and Corbin, 1998). The secondary data included, among others, newsletters, promotional materials, websites, social media pages, and business reports of both the global leading organizations on the related market (e.g., Zipcar, Mobike, Lime) as well as the organizations mentioned during the interviews. Additionally, two general managers of the organization that was the most 
frequently mentioned by respondents in the qualitative study and that appeared, at that time, to be the leader on the national car-sharing market, were interviewed. During these interviews, the insights gained from the customer interviews were discussed and managers were asked to confront these insights with their business practices. These data not only helped the authors triangulate the customer interview data and illustrate organizational practices that the respondents were referring to, but also assess the validity of the identified desired design choices (Strauss and Corbin, 1998). This car-sharing organization (named 'Organization A') serves as an example case throughout the presentation and discussion of the results, with the ultimate goal of further clarifying and extending understanding of the research phenomenon under the investigation (Yin, 2017).

For the researcher triangulation (for a similar procedure, see for instance Ulaga and Reinartz, 2011), the authors discussed the coding plan and jointly categorized the results while ensuring internal consistency and seeking agreement through discussion. In addition, two independent judges — both familiar with qualitative research—were asked to assign statements to the abstract categories developed by the authors to ensure the reliability of the categorization. The interjudge reliability — assessed following the Proportional Reduction in Loss measurereached 0.81 , which is well above the 0.70 threshold recommended for exploratory research (Rust and Cooil, 1994). Finally, the results were discussed with recognized experts in the field, before being presented during an academic research seminar, to ensure clarity of the conceptualization. Overall, both the analytical process and the validity assessment of the results provides the authors with the confidence that the findings capture the key design choices that customers expect organizations to make for risk management and PSS operation in the sharing economy.

\section{Findings}


The integrative conceptual framework synthesizes the strategic design choices, nested in the meta-categories "Structural" and "Infrastructural" design aspects, that customers believe organizations should make to manage risks for sharing-based PSS operation (see Figure 2). While some strategic design choices overlap with prior research findings, other desired design choices seem to be specific to sharing-based PSS. The conceptual model further reveals several contingency factors and sheds light on the complex relationship between risk management (and the related service design choices) and customers' sense of trust, control perceptions, as well as customer-perceived value. Owing to constraints of space, only the new concepts and effects uncovered by this research are presented in more detail and discussed against prior research. This approach leads to the formulation of four key research propositions that together add deeper explanations to the scarce literature on sharing-based PSS.

[Insert FIGURE 2 around here]

\subsection{What service delivery design choices do customers expect organizations to make in order to manage risks for sharing-based PSS operation?}

The empirical findings clearly show the importance of considering service design elements to manage risks and ensure smooth operation of sharing-based PSS. In particular, the interview data suggest customers expect organizations to avoid, share, or reduce risks in the sharing economy through both structural and infrastructural design elements. Previous studies implicitly suggest a link between risk management and structural design aspects related to process, technology, and equipment (e.g., proactive maintenance, good data and information handling, use of sensors; Isaksson et al., 2009; Reim et al., 2016; Roy and Cheruvu, 2009; Steven, 2012). The empirical data reveal additional structural design elements that would help organizations manage risks in the sharing economy, including location, layout as well as capacity-related design elements. For instance, organizations could decrease the frequency or severity of potential losses (i.e., risk reduction approach) through-among others-remote 
monitoring of product location and condition, proactive data-driven fleet management (i.e., maintenance, repair, cleaning, and replacement), or the use of environmental cues for organizational socialization (see Figure 2 for other specific customer-based design choices identified in this study). Interestingly, such design choices would not only help organizations reduce operational risks, but also enhance customer-perceived benefits and value. As illustrated in the statement below, organizations could mitigate risks and make better value propositions by constantly improving the service design based on the feedback they receive from customers. Put differently, the results suggest that PSS risk management and service design are dynamic learning processes directed at improving customer-perceived value.

You never knew when and where a bike was available [delivery risk for the organization]. This was such an issue. But what's great with the bike-sharing now, they recently developed a new mobile application. Of course, you need the Internet, but thanks to this app you can see how many bikes there are at the station, how many places left, and where the stations are. (ID 39, current bike-sharing user)

Both structural and infrastructural design choices may also serve as risk avoidance and risk sharing approaches, considered as typical risk response strategies in the risk management literature (e.g., Reim et al., 2016). For instance, organizations offering sharing-based PSS could avoid the possibility that risks occur (i.e., risk avoidance approach) by carefully selecting customers throughout a strict registration procedure. Organization A, which serves as an example case in this study, specifically requires customers to provide a copy of their identity card, driving license, and bank account. Moreover, customers must be at least 25 years old and have held their driving license for at least two years. Potential customers must also pay a rather high (refundable) deposit as part of the registration procedure, and pass a dedicated training session to become an official member of Organization A's car-sharing program. The organization assumes that a stricter and more complex registration procedure decreases the likelihood of technical and behavioral issues or risks. As one respondent noted, the complexity 
of the registration procedure represents a barrier to entry that is necessary for attracting only people who are part of the target group, who really need the service and would comply with the rules. This procedure, on the other hand, creates a paradoxical situation for organizations who need to maximize the number of customers in order to survive in the sharing economy.

I guess there must be a specific target group. In my opinion it should be rather selective, in terms of price or deposit for instance so the users are not those stupid guys who wouldn't take care of the products and... I guess they don't accept everyone! (ID 28, potential user)

Although the respondents wanted organizations to make changes in the service design as a way to ensure PSS operation and enhance perceived value, organizations should yet be careful when making such design choices. Some of these changes might create some frictions in the customer experience. For instance, implementing a reservation system may help organizations reduce delivery risks and customer-perceived uncertainty related to product availability (or product scarcity) (Lamberton and Rose, 2012) — especially when the number of available products is limited in terms of quantity. However, such a capacity-related design element also forces customers to engage in self-organizing (i.e., planning one's needs in advance so as to reserve the product) that they consider burdensome (Hazée et al., 2017).

Overall, the empirical findings about the relationship between service delivery system design and risk management in sharing-based PSS are summarized as follows:

Proposition 1: Strategic design choices (reflected in both structural and infrastructural design aspects) mitigate risks faced by sharing-based PSS providers and ultimately enhance customer-perceived value.

From the interviews, there is also substantial evidence for the importance of influencing customer trust and control for sharing-based PSS operation. Trust and control are two important mechanisms that can influence customer behavior within PSS (Reim et al., 2018) and are considered key to the success of lateral exchange markets such as the sharing economy (Perren 
and Kozinets, 2018). As such, Field et al. (2018) call for more research on how organizations could design and manage their sharing services to influence customer intended behavior as well as customers' sense of trust and control perceptions. The data reveal all strategic design choices, both structural and infrastructural, that organizations may make to manage risks for sharing-based PSS operation can supplement each other and indirectly influence customerperceived value through customers' sense of trust and/or control perceptions. As two respondents noted:

Well the company maintains the cars, they are regularly checked up and cleaned I think, it's also cleaned inside so... I'd say the company guarantees a regular maintenance of the fleet, so it makes me think they do their best for us. (ID 38, current car-sharing user)

I think one way to overcome complexity would be to have access to the same cars, wherever you are. I mean there would be different categories, small city cars and vans for moving stuff, but... yeah... so each time you'd use the service, you'd know how to use it, and others too. (ID 22, potential user)

As indicated in the above statements, strategic design choices such as proactive maintenance of shared products or product portfolio standardization would not only bolster customer trust in the focal organization (as reflected in the organization's expected benevolence, "they do their best for us"), but also customer control perceptions over the process and customer trust in other users (as reflected in customer's expectations of one's and other users' competence, or ability to use the shared products), which in turn would ensure smooth PSS operation and enhance customer-perceived value. Given the triadic nature of sharing-based PSS, which implies - as previously argued-that production not only flows from organizations to customers and from customers to organizations (Sampson and Froehle, 2006), but also from customers to customers, respondents mentioned the importance of their trust and control perceptions in relation to all actors involved in the service delivery system, that is, both the focal organization and other PSS users: 
In such services, it's not only about the company, but also other users... I don't know in what state they would drop back the goods after using them for example... I don't know if we can control this in some way, if the company does it or not? (ID 23, potential user)

Research suggests that monitoring mechanisms are exclusively control-oriented (e.g., Davis et al., 1997; Reim et al., 2018; Schepers et al., 2012). The findings suggest such monitoring mechanisms can influence not only customer control perceptions, but also bolster trust in other PSS users. For instance, some participants considered other users as opportunistic actors and thereby expected organizations to design their service in such a way as to monitor customers and prevent opportunism (i.e., behavioral risks). Although such design decisions are typically considered as control (or monitoring) mechanisms (Reim et al., 2018), the data show they can also encourage customers' sense of trust in other PSS users through interpersonal similarity beliefs, suggesting the need for organizations to systematically take into consideration both customers' sense of trust and control perceptions when designing their sharing-based PSS solution. Put differently, complementing Reim et al.'s (2018) findings, this study shows that strategic design choices may not only serve as monitoring, control-based mechanisms, but also as trust mechanisms in PSS risk management. As one respondent noted:

I do think this is necessary [implementing a control system] if you want such services to work $[\ldots]$ in my opinion you can also find the sharing or trust aspect in this [collaborative control] system, I mean it's a matter of social responsibility, everyone participates on an equal footing, someone will check the product you used, and you will do so too. (ID 27, potential user) As highlighted in the above statement, customers are ready to take on extra roles in the PSS production process. Echoing Bardhi and Eckhardt's (2012) findings, the data show customers are indeed willing to collaborate with the organization and monitor the product condition. Organizations could thus further reduce risks by facilitating such co-production behaviors and designing their processes accordingly. For instance, the car fleet made available to customers by Organization $\mathrm{A}$ is equipped with user-friendly technological systems that allow customers 
to report, before using the service, any damage to the car. Given the increasingly high interdependence and participatory role of customers in sharing-based PSS, it is noteworthy to mention that the data suggest organizations not only need to carefully monitor behaviors through specific processes and technology, but also require more traditional back-office support-compared with traditional (low-contact) service supply chains-as a means to manage risks.

The preceding discussion of the importance of customer trust and control for risk management and sharing-based PSS operation is summarized in the following propositions:

Proposition 2: Strategic structural and infrastructural design decisions may serve as both control and trust mechanisms in PSS risk management.

Proposition 3: Within sharing-based PSS, the effects of strategic structural and infrastructural design choices on customer-perceived value are mediated by customers' trust and control perceptions in relation to all actors involved in the service delivery system (i.e., both the focal organization and other users).

\subsection{What are the contingency factors upon which risk management approaches (and related customer-based design choices) depend?}

Contingency theory posits that organizations may align with changing contextual factors and adapt their structures accordingly to maximize performance (Donaldson, 2001). The results reveal that some risk management approaches and related operations design choices may be more (or less) recommended in specific situations. Integrating prior research in operations management (e.g., Sousa and Voss, 2008) and sharing economy (e.g., Perren and Kozinets, 2018), among others, this study identifies three relevant customer-based contingency factors that may play a role when making operations management decisions for design and risk management in the sharing economy. These contingency factors relate to the sharing value 
proposition, the customer-perceived level of consequentiality, and the level of customersupplied resources.

Echoing prior research on the service strategy triad (e.g., Ponsignon et al., 2011), the first contingency factor highlights the importance of the sharing value proposition, or service concept (Zomerdijk and de Vries, 2007), for operational design decisions. The term 'sharing economy' reflects a diversity of sharing models that may differ on various characteristics (Wirtz et al., 2019). Sharing-based PSS models may either be economically motivated and involve transfer of economic value from one entity to another (Kumar et al., 2018), or more socially-driven with no expectation of payment (e.g., couchsurfing; Belk, 2010). In the former case, sharing-based PSS offer value propositions that give more prominence to tangible value aspects such as cost-savings, ownership substitutability and convenience. In the latter case, the intangible value aspects of sharing (hedonic and social value) predominate (Akbar and Hoffmann, 2020). The data suggest customers expect organizations to align their risk management approach and related strategic design choices with their sharing value proposition. Customers expect organizations to manage risks by making design decisions that foster either interpersonal trust or control depending on their sharing value proposition. For instance, customers expect the desired level of formality of customer resource policies (e.g., rewards and sanctions) and of remote monitoring of shared products to be lower in PSS that offer sociallydriven value proposition. As one respondent explained:

At the beginning, people... users were like defenders of this social system. Now this is different, the company is growing and attracts more and more people who are different $[\ldots]$ Before, we did not have to systematically check the cars. The shift to a more commercial attitude has changed the whole system. (ID 15, lost car-sharing user)

The second contingency factor relates to customer-perceived level of consequentiality. Service (mis)performance may have significant consequences for customers and ultimately impact perceived value (Singh and Sirdeshmukh, 2000). As highlighted in the statement below, 
respondents expressed much more concern about the potential negative (e.g., financial or physical) consequences of service (mis)performance in the case of car-sharing programs, compared with bike- and toy-sharing programs, and therefore expected organizations to favor a complementary combination of risk avoidance (e.g., selecting only customers who have a minimum of 2-year driving experience), sharing (e.g., insurance policy), and reduction approaches (e.g., remote monitoring of products) for effective PSS operation:

Cars are too valuable and can lead to far more problems compared with bikes. When you use bike-sharing, at worst someone has spilled something on your saddle, or the handlebar is greasy... With bikes, you can quickly check if the tire is punctured or not, if the chain's working... Sharing cars is a different story! [...] and the same goes for tools! This is too dangerous! What if the power drill is defective?! (ID 27, potential user)

The data suggest that the perceived level of consequentiality is closely related to the type of product that is made available to customers through sharing-based PSS. Reim et al. (2016) argue it is more appropriate to share risks with customers in those situations where (financial) consequences of technical malfunction are significant, which is typically the case for new, custom-made (versus standardized, high-volume) products. Complementing Reim et al.'s (2016) findings, the present data suggest that organizations should not only share risks with customers when the perceived level of consequentiality (associated with the type of product) is high, but also make strategic design choices to avoid and reduce risks. On the opposite, there is less need for a combination of risk management approaches when the level of customerperceived consequentiality is low.

The third factor upon which risk management approaches and related PSS design choices are contingent is the level of customer-supplied resources. The general theoretical understanding in the literature is that high levels of customer-supplied resources lead to higher productivity, enhanced service quality, and increased customer-perceived value (e.g., Mustak et al., 2013; Johnston, 1989). The data however suggest the more customer-supplied resources, 
the higher the risks for organizations. As previously argued, with sharing-based PSS, production flows from customers to customers who act as suppliers of resources for one another. Sharing-based PSS either provide customers with access to products that remain in an organization's ownership (e.g., bike- and car-sharing programs), or make privately owned goods available to other people within a community (e.g., peer-to-peer accommodation) (Piscicelli et al., 2015). In the latter case, resources are not directly supplied by the focal organization but rather crowdsourced from many individual customers (Wirtz et al., 2019), who take on the role of peer service providers. As exemplified by leading organizations operating on the sharing economy market, risk avoidance (e.g., only offering a PSS without being responsible for technical issues) and sharing approaches (e.g., conditional contract, insurance policy) are given more weight when the level of customer-supplied resources is high.

Based on these findings and their discussion against prior research, the following research proposition is presented:

Proposition 4: Within sharing-based PSS, risk management approaches and their related strategic design choices vary according to (a) the sharing value proposition, (b) customerperceived level of consequentiality, and (c) level of customer-supplied resources.

\section{General discussion}

\subsection{Theoretical contributions}

Despite the importance of understanding the operational implications of the sharing economy, prior research provides limited insights into this issue (Victorino et al., 2018). Field et al. (2018) recently introduced important challenges of the sharing economy for operations management. This study connects with their conceptual work by providing customer-based insights into operations management, in particular risk management and PSS design, for sharing-based PSS operation. In doing so, this research responds to recent calls for more 
research on the interconnection between PSS and the sharing economy (Annarelli et al., 2016). This study contributes to the literature in two main ways.

First, this research bridges the emerging PSS risk management literature with the service delivery system design research area by empirically revealing that customer-based strategic design choices can serve as risk management approaches for sharing-based PSS operation. As Field et al. (2018) point out, the management of risks is one of the key challenges in designing and running sharing-based PSS. These risks need to be carefully managed for PSS success (e.g., Benedettini et al., 2015; Erkoyuncu et al., 2013). Previous studies implicitly suggest a link between PSS risk management and structural design aspects such as proactive maintenance, the use of sensors as well as good data and information handling (e.g., Isaksson et al., 2009; Reim et al., 2016; Roy and Cheruvu, 2009; Steven, 2012). This study integrates these partial, fragmented discussions of risk management in the PSS literature into a comprehensive conceptual framework. This framework further reveals what structural and infrastructural design choices customers expect organizations to make for mitigating risks and ultimately enhancing customer-perceived value in the sharing economy. Such a framework is found particularly relevant and timely as organizations generally face increased risks when providing sharing-based PSS — due to the increasingly complex service delivery system and enhanced role of customers in the delivery process (Damali et al., 2020; Field et al., 2018; Hazée et al., 2017).

Moreover, this study accounts for the particularities of sharing-based PSS and extends prior research on traditional service supply chains (e.g., Sampson, 2000; Sampson and Spring, 2012). This study proposes that production in the sharing economy not only flows from organizations to customers and from customers to organizations, but also from customers to customers who act as suppliers of resources for one another. Field et al. (2018) recognize this complexity, as they consider the design and management of operational processes to influence 
customer behavior in the sharing economy as a key challenge that operations managers face in this context. Given the triadic nature of sharing-based PSS, this study reveals the importance of influencing customers' sense of trust and control perceptions in relation to all actors involved in the service delivery system, that is both the focal organization and other PSS users. Furthermore, this paper identifies the customer-based strategic design choices that may influence customers' trust and control perceptions in sharing-based PSS. Building upon and extending the risk management literature, this study further shows that strategic design choices such as product monitoring may not only serve as control-based mechanisms (e.g., Reim et al., 2018), but also as trust mechanisms in PSS risk management. The results indeed show such monitoring processes encourage customers' sense of trust in other PSS users through interpersonal similarity beliefs, suggesting the need for organizations to systematically take into consideration both customers' sense of trust and control perceptions when designing and managing their sharing-based PSS solution.

Second, this research contributes to the ongoing discussion on the contingency aspects of PSS (e.g., Kohtamäki et al., 2013; Reim et al., 2016) and service delivery system design (e.g., Contiero et al., 2016; De Regge et al., 2019; Ponsignon et al., 2011). In particular, this study highlights under which conditions specific risk management approaches (and the related operations design choices) may be more (or less) recommended in the sharing economy. Complementing prior operations management research that mainly uses a firm-oriented approach and focuses on firm characteristics and environmental contingencies (e.g., firm size, strategic context, national context, culture; Sousa and Voss, 2008; Smith et al., 2012), the present paper uses a customer-oriented approach and identifies key customer-based criteria that provide guidance for selecting appropriate PSS design elements and risk management approaches. In particular, the present study finds that sharing value proposition, customerperceived level of consequentiality, and level of customer-supplied resources are important 
criteria that need consideration when making design decisions for risk management in the sharing economy. Echoing previous discussions in literature on the importance of considering the human side in operations management (e.g., Pawar et al., 2009; Smith et al., 2014), this study suggests understanding both the organizational context and customers' individual context is critical for (contingency) theory and practice, as it can reveal new situations where operations design choices and risk management practices are more or less effective. Complementing common wisdom that suggests higher degrees of customer participation lead to higher productivity and customer-perceived value (e.g., Mustak et al., 2013; Johnston, 1989), this study reveals that high levels of customer-supplied resources may backfire and create operational risks for organizations in the sharing economy.

\subsection{Managerial implications}

More and more organizations differentiate and generate new revenue streams by developing and offering sharing services as a servitization strategy. However, offering a sharing-based PSS creates a set of significant operational challenges and risks for organizations, which urgently and carefully need to be addressed for the PSS success. The present results accordingly provide valuable insights for those organizations that offer, or plan to offer, such PSS solutions. In particular, managers can use this study's results to identify strategic design choices that customers expect them to make for sharing-based PSS operation. Interestingly, this research reveals such design choices serve as unique risk management approaches. Sharing-based PSS providers might thus use the framework developed in this study (see Figure 2) to check the specific customer-based design choices that are likely to mitigate operational risks and enhance customer-perceived value. The findings, grounded in field data, provide fruitful examples of such operations decisions. Because organizations can always do better at mitigating risks, managers could use a similar customer-oriented approach as this study to continuously obtain feedback from customers and improve the service design accordingly. 
Regardless of the type of shfbelowaring-based PSS that is offered (e.g., bike- or carsharing), organizations should be aware of the important roles of customers' trust and control perceptions when designing and managing PSS. Results reveal that all strategic design choices identified in this study may influence customers' sense of trust and control perceptions, which relate to all actors involved in the service delivery system. In certain situations, however, specific risk management approaches (and related design choices) may be more (or less) appropriate for sharing-based PSS operation. This study identifies three key criteria related to the organizational context as well as customers' individual context-namely sharing value proposition, customer-perceived level of consequentiality, and level of customer-supplied resources - that should help organizations make accurate, informed operations decisions based on customer insights.

\subsection{Limitations and future research directions}

As with any study, it is important to note several limitations, some of which offer potential fruitful avenues for future research. First, because this work is qualitative and exploratory in nature, an empirical quantitative validation of the research propositions is necessary to further ensure generalizability. Next to the verification of the propositions, future research could examine the relative impact of specific customer-based design choices on customer-perceived value associated with sharing-based PSS. Such investigations would provide operations managers with relevant insights on how to best design and manage their PSS offering. Second, this study predominantly considers operational risks holistically, while previous studies conceptualize operational risks as a multidimensional construct (e.g., Reim et al., 2016). Examining the relative impact of the customer-based strategic design choices identified in this study on certain specific risks (i.e., behavioral, technical, and delivery competence risks) is a logical next step. Third, the sharing economy literature suggests that sharing business models may vary along various characteristics including, among others, sharing temporality, 
anonymity, and platform mediation (e.g., Perren and Kozinets, 2018; Wirtz et al., 2019). Future research could investigate in detail whether and how these business model characteristics influence risk management as well as PSS design choices. 
Figure 1: Traditional (service) supply chain versus sharing service supply chain

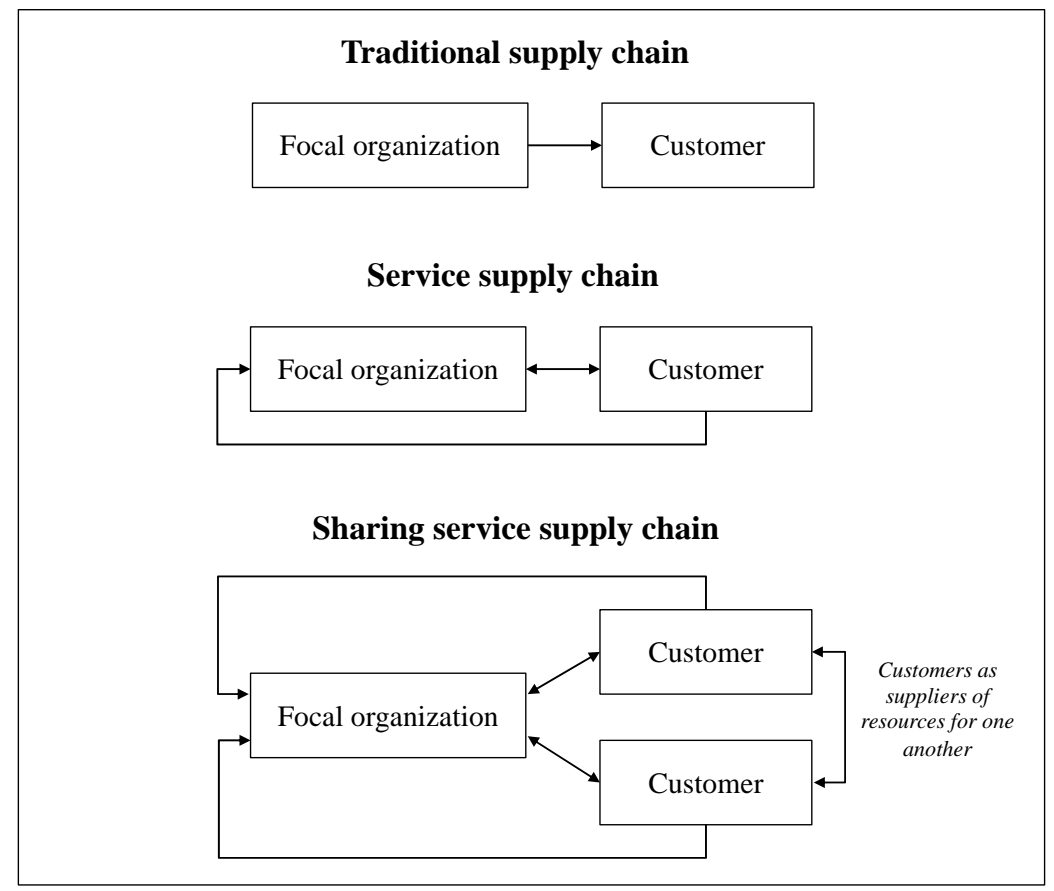

Source: Adapted from Sampson and Spring (2012) 
Figure 2: Integrative conceptual framework

\section{Customer-based strategic design choices $(R Q 1)$}

Structural aspects

Facility, location, and layout

- Environmental cues for organizational socialization

- Focus on digitalized touchpoints

- Level of visibility \& accessibility of pick-up points

Process, technology, and equipment

- Remote co-monitoring of product location, condition, and use, coupled with a reputation system

- Proactive data-driven asset management (e.g., maintenance)

- Level of diversification \& standardization of product portfolio

- Level of remote front-office support

\section{Capacity}

- Level of supplied \& backup assets

- Reservation system

- Off-peak pricing \& promotions

\begin{tabular}{|l|}
\hline Infrastructural aspects \\
\hline People \\
- Level of front-line employees' interactive (and technical) skills \\
- Level of customers' technical skills \\
Policy, procedure, and protocol \\
- Customer resource policies (e.g., level of selectivity, training \\
- procedure, formality of rewards and sanctions) \\
- Orvice recovery guarantees \\
- Registrational procedure (incl. conditional contract and \\
refundable deposit policy) \\
\hline
\end{tabular}

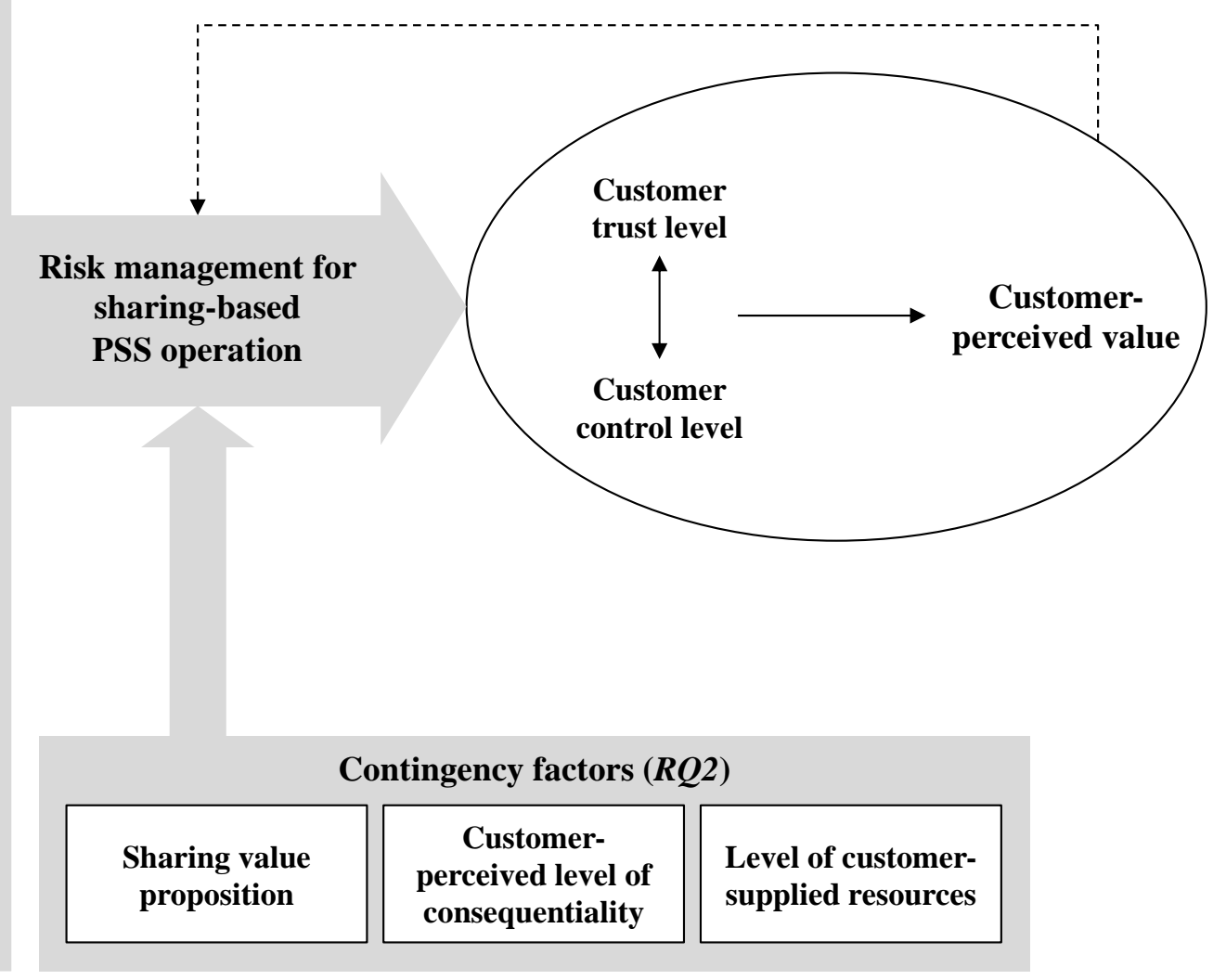




\section{Appendix 1: Summary of the depth-interview respondents}

\begin{tabular}{|c|c|c|c|c|c|c|}
\hline ID $^{\mathbf{a}}$ & Gender & Age & $\begin{array}{l}\text { Relationship and family } \\
\text { status }\end{array}$ & Profession & $\begin{array}{l}\text { PSS user } \\
\text { profile }\end{array}$ & $\begin{array}{l}\text { Main PSS } \\
\text { used* }\end{array}$ \\
\hline 1 & $\mathrm{~F}$ & 33 & Cohabiting (two children) & Employed & Lost & Car \\
\hline 2 & $\mathrm{~F}$ & 24 & Cohabiting & Employed & Lost & Car \\
\hline 3 & M & 27 & Cohabiting & Employed & Lost & Bike \\
\hline 4 & $\mathrm{~F}$ & 45 & Single & Employed & Lost & Car \\
\hline 5 & $\mathrm{~F}$ & 54 & Married & Employed & Lost & Car \\
\hline 6 & $\mathrm{M}$ & 26 & Single & Employed & Lost & Car \\
\hline 7 & $\mathrm{~F}$ & 26 & Single & Employed & Lost & Bike \\
\hline 8 & M & 34 & Single & Unemployed & Lost & Car \\
\hline 9 & $\mathrm{~F}$ & 29 & Cohabiting (one child) & Employed & Lost & Car \\
\hline 10 & $\mathrm{~F}$ & 40 & Single & Employed & Lost & Car \\
\hline 11 & M & 35 & Single (one child) & Employed & Lost & Car \\
\hline 12 & M & 24 & Single & Employed & Lost & Car \\
\hline 13 & $\mathrm{~F}$ & 62 & Cohabiting (two children) & Employed & Lost & Car \\
\hline 14 & M & 43 & Cohabiting (two children) & Employed & Lost & Car \\
\hline 15 & M & 60 & Married (four children) & Employed & Lost & Car \\
\hline 16 & M & 38 & Cohabiting (one child) & Employed & Lost & Car \\
\hline 17 & $\mathrm{~F}$ & 41 & Cohabiting (one child) & Employed & Lost & Car \\
\hline 18 & $\mathrm{M}$ & 33 & Cohabiting & Employed & Potential & I \\
\hline 19 & $\mathrm{~F}$ & 51 & Cohabiting & Employed & Potential & l \\
\hline 20 & $\mathrm{~F}$ & 29 & Cohabiting & Employed & Potential & l \\
\hline 21 & M & 27 & Single & Employed & Potential & l \\
\hline 22 & $\mathrm{~F}$ & 26 & Cohabiting & Employed & Potential & l \\
\hline 23 & $\mathrm{~F}$ & 24 & Cohabiting & Employed & Potential & l \\
\hline 24 & M & 31 & Cohabiting & Employed & Potential & l \\
\hline 25 & M & 28 & Single & Unemployed & Potential & l \\
\hline 26 & M & 30 & Married & Employed & Potential & l \\
\hline 27 & M & 26 & Cohabiting & Employed & Potential & l \\
\hline 28 & $\mathrm{~F}$ & 24 & Cohabiting & Employed & Potential & l \\
\hline 29 & M & 26 & Single & Employed & Potential & l \\
\hline 30 & $\mathrm{~F}$ & 47 & Single (two children) & Employed & Potential & l \\
\hline 31 & M & 25 & Single & Employed & Potential & l \\
\hline 32 & M & 45 & Cohabiting & Employed & Potential & l \\
\hline 33 & $\mathrm{~F}$ & 65 & Single & Retired & Potential & / \\
\hline 34 & $\mathrm{~F}$ & 46 & Cohabiting (four children) & Employed & Potential & l \\
\hline 35 & M & 60 & Cohabiting (one child) & Retired & Potential & l \\
\hline 36 & M & 72 & Cohabiting & Retired & Potential & l \\
\hline 37 & M & 38 & Cohabiting (two children) & Employed & Current & Car \\
\hline 38 & $\mathrm{~F}$ & 29 & Cohabiting & Employed & Current & Car \\
\hline 39 & M & 27 & Cohabiting & Employed & Current & Bike \\
\hline 40 & M & 25 & Cohabiting & Employed & Current & Bike \\
\hline 41 & $\mathrm{~F}$ & 34 & Cohabiting & Employed & Current & Car \\
\hline 42 & $\mathrm{~F}$ & 26 & Single & Employed & Current & Car \\
\hline 43 & $\mathrm{M}$ & 45 & Single (two children) & Employed & Current & Car \\
\hline 44 & $\mathrm{~F}$ & 24 & Single & Employed & Current & Bike \\
\hline 45 & $\mathrm{~F}$ & 33 & Cohabiting & Employed & Current & Car \\
\hline 46 & M & 25 & Single & Student & Current & Bike \\
\hline 47 & $\mathrm{~F}$ & 30 & Single & Employed & Current & Car \\
\hline 48 & $\mathrm{~F}$ & 30 & Single & Employed & Current & Car \\
\hline 49 & $\mathrm{~F}$ & 47 & Single (one child) & Employed & Current & Car \\
\hline 50 & M & 45 & Cohabiting & Employed & Current & Car \\
\hline 51 & $\mathrm{~F}$ & 31 & Single & Employed & Current & Car \\
\hline 52 & M & 39 & Cohabiting & Employed & Current & Car \\
\hline 53 & $\mathrm{~F}$ & 38 & Married (two children) & Employed & Current & Car \\
\hline 54 & $\mathrm{~F}$ & 36 & Single & Employed & Current & Car \\
\hline 55 & $\mathrm{~F}$ & 55 & Single & Employed & Current & Car \\
\hline 56 & $\mathrm{~F}$ & 28 & Cohabiting & Employed & Current & Car \\
\hline
\end{tabular}

Notes. IDs are used to protect the respondents' identity. *Some respondents use (or had used) various types of PSS, yet — for the sake of clarity — only the PSS that is (has) being used (and/or referred to during the interviews) the most frequently is mentioned in this table. 


\section{References}

Akbar, P. and Hoffmann, S. (2020), "Creating value in product service systems through sharing", Journal of Business Research, in press, pp. 1-11.

Andreassen, T., Lervik-Olsen, L., Snyder, H., Van Riel, A.C.R., Sweeney, J.C., and Van Vaerenbergh, Y. (2018), "Business model innovation and value-creation: The triadic way”, Journal of Service Management, Vol. 29 No. 5, pp. 883-906.

Annarelli, A., Battistella, C. and Nonino, F. (2016), "Product service system: A conceptual framework from a systematic review", Journal of Cleaner Production, Vol. 139, pp. 10111032.

Baines, T. and Lightfoot, H.W. (2014), "Servitization of the manufacturing firm: exploring the operations practices and technologies that deliver advanced services", International Journal of Operations \& Production Management, Vol. 34 No. 1, pp. 2-35.

Baines, T., Lightfoot, H., Peppard, J., Johnson, M., Tiwari, A., Shehab, E. and Swink, M. (2009), “Towards an operations strategy for product-centric servitization", International Journal of Operations \& Production Management, Vol. 29 No. 5, pp. 494-519.

Bardhi, F. and Eckhardt, G.M. (2012), “Access-based consumption: The case of car sharing”, Journal of Consumer Research, Vol. 39 No. 4, pp. 881-898.

Belk, R.W. (2014), "You are what you can access: Sharing and collaborative consumption online”, Journal of Business Research, Vol. 67 No. 8, pp. 1595-1600.

Belk, R.W. (2010), “Sharing”, Journal of Consumer Research, Vol. 36 No. 5, pp. 715-734.

Benedettini, O., Swink, M. and Neely, A. (2015), "Why do servitized firms fail? A risk-based explanation", International Journal of Operations \& Production Management, Vol. 35 No. 6, pp. 946-979. 
Beuren, F.H., Ferreira, M.G.G. and Miguel, P.A.C. (2013), "Product-service systems: A literature review on integrated products and services", Journal of Cleaner Production, Vol. 47, pp. 222-231.

Botsman, R. and Rogers, R. (2011), What's mine is yours: How collaborative consumption is changing the way we live, Collins, London.

Bowen, G.A. (2008), "Naturalistic inquiry and the saturation concept: A research note", Qualitative Research, Vol. 8 No. 1, pp. 137-152.

Braun, V. and Clarke, V. (2006), "Using thematic analysis in psychology", Qualitative Research in Psychology, Vol. 3 No. 2, pp. 77-101.

Contiero, E., Ponsignon, F., Smart, P. and Vinelli, A. (2016), "Contingencies and characteristics of service recovery system design: Insights from retail banking", International Journal of Operations \& Production Management, Vol. 36 No. 11, pp. 16441667.

Damali, U., Secchi, E., Tax, S. and McCutcheon, D. (2020), "Customer participation risk management: Conceptual model and managerial assessment tool", Journal of Service Management, in press, pp. 1-25.

Das, T.K. and Teng, B.-S. (1998), "Between trust and control: Developing confidence in partner cooperation in alliances", Academy of Management, Vol. 23 No. 3, pp. 491-512.

Davis, J.H., Schoorman, D.F. and Donaldson, L. (1997), “Toward a stewardship theory of management”, Academy of Management Review, Vol. 22 No. 1, pp. 20-47.

De Regge, M., Gemmel, P. and Meijboom, B. (2019), "How operations matters in healthcare standardization”, International Journal of Operations \& Production Management, Vol. 39 No. 9/10, pp. 1144-1165.

Donaldson, L. (2001), The Contingency Theory of Organizations, Sage Publications, Thousand Oaks, CA. 
Dorfman, M.S. (1998), Introduction to Risk Management and Insurance, Pearson Higher Education, New York, NY.

Erkoyuncu, J.A., Durugbo, C. and Roy, R. (2013), “Identifying uncertainties for industrial service delivery: A systems approach", International Journal of Production Research, Vol. 51 No. 21, pp. 6295-6315.

Field, J., Victorino, L., Buell, R., Dixon, M., Meyer Goldstein, S., Menor, L., Pullman, M., Roth, A., Secchi, E. and Zhang, J. (2018), “Service operations: What's next?”, Journal of Service Management, Vol. 29 No. 1, pp. 55-97.

Firnkorn, J. and Müller, M. (2012), "Selling mobility instead of cars: New business strategies of automakers and the impact on private vehicle holding", Business Strategy and the Environment, Vol. 21 No. 4, pp. 264-280.

Frei, F. (2006), "Breaking the trade-off between efficiency and service", Harvard Business Review, Vol. 84 No. 11, pp. 92-101.

Goedkoop, M., van Halen, C., te Riele, H. and Rommens, P. (1999), Product Service Systems, Ecological and Economic Basics, VROM, The Hague.

Hazée, S., Delcourt, C. and Van Vaerenbergh, Y. (2017), "Burdens of access: Understanding customer barriers and barrier-attenuating practices in access-based services", Journal of Service Research, Vol. 20 No. 4, pp. 441-456.

Hazée, S., Van Vaerenbergh, Y., Delcourt, C., and Warlop, L. (2019), "Sharing goods? Yuck, no! An investigation of consumers' contamination concerns about access-based services," Journal of Service Research, Vol. 22 No. 3, pp. 256-271.

Homburg, C., Jozić, D. and Kuehnl, C. (2017), “Customer experience management: Toward implementing an evolving marketing concept", Journal of the Academy of Marketing Science, Vol. 45 No. 3, pp. 377-401. 
Isaksson, O., Larsson, T.C. and Rönnbäck, A.Ö. (2009), "Development of product-service systems: Challenges and opportunities for the manufacturing firm", Journal of Engineering Design, Vol. 20 No. 4, pp. 329-348.

Johnston, R. (1989), "The customer as employee", International Journal of Operations \& Production Management, Vol. 9 No. 5, pp. 15-23.

Johnstone, S., Dainty, A. and Wilkinson, A. (2009), "Integrating products and services through life: An aerospace experience", International Journal of Operations \& Production Management, Vol. 29 No. 5, pp. 520-538.

Kohtamäki, M., Partanen, J., Parida, V. and Wincent, J. (2013), "Non-linear relationship between industrial service offering and sales growth: The moderating role of network capabilities”, Industrial Marketing Management, Vol. 42 No. 8, pp. 1374-1385.

Kumar, V., Lahiri, A. and Dogan, O.B. (2018), “A strategic framework for a profitable business model in the sharing economy", Industrial Marketing Management, Vol. 69 No. 2, pp. 147-160.

Lamberton, C.P. and Rose, R.R. (2012), "When is ours better than mine? A framework for understanding and altering participation in commercial sharing systems", Journal of Marketing, Vol. 76 No. 4, pp. 109-125.

McCracken, G. (1988), The Long Interview, (Qualitative Research Methods Series 13), Newbury Park, CA: Sage Publications.

Meredith, J., Raturi, A., Amoako-Gyampah, K. and Kaplan, B. (1989), “Alternative research paradigms in operations", Journal of Operations Management, Vol. 8 No. 4, pp. 297-326.

Mont, O. (2002), "Clarifying the concept of product-service system", Journal of Cleaner Production, Vol. 10 No. 3, pp. 237-245. 
Mustak, M., Jaakkola, E. and Halinen, A. (2013), "Customer participation and value creation: A systematic review and research implications", Managing Service Quality, Vol. 23 No. 4, 341-359.

Neely, A. (2009), "Exploring the financial consequences of the servitization of manufacturing”, Operations Management Research, Vol. 1 No. 2, pp. 103-118.

Ng, I.C., Ding, D.X. and Yip, N. (2013), "Outcome-based contracts as new business model: The role of partnership and value-driven relational assets", Industrial Marketing Management, Vol. 42 No. 5, pp. 730-743.

Oliva, R. and Kallenberg, R. (2003), "Managing the transition from products to services", International Journal of Service Industry Management, Vol. 14 No. 2, pp. 160-172.

Patton, M.Q. (2014), Qualitative Research \& Evaluation Methods. Thousand Oaks, CA: Sage.

Pawar, K.S., Beltagui, A. and Riedel, J. (2009), “The PSO triangle: Designing product, service and organisation to create value", International Journal of Operations \& Production Management, Vol. 29 No. 5, pp. 468-493.

Perren, R. and Kozinets, R.V. (2018), "Lateral exchange markets: How social platforms operate in a networked economy", Journal of Marketing, Vol. 82 No. 1, pp. 20-36.

Piscicelli, L., Cooper, T. and Fisher, T. (2015), "The role of values in collaborative consumption: Insights from a product-service system for lending and borrowing in the UK”, Journal of Cleaner Production, Vol. 97, pp. 21-29.

Ponsignon, F., Smart, P.A. and Maull, R.S. (2011), "Service delivery system design:

Characteristics and contingencies", International Journal of Operations \& Production Management, Vol. 31 No. 3, pp. 324-349.

PriceWaterhouseCoopers (2014), "Five key sharing economy sectors could generate $£ 9$ billion of UK revenues by 2025”, Retrieved February 8, 2019 from 
http://pwc.blogs.com/press_room/2014/08/five-key-sharing-economy-sectors-couldgenerate-9-billion-of-uk-revenues-by-2025.html.

Reim, W., Parida, V. and Örtqvist, D. (2015), "Product-service systems (PSS) business models and tactics-A systematic literature review”, Journal of Cleaner Production, Vol. 97, pp. $61-75$.

Reim, W., Parida, V. and Sjödin, D. R. (2016), "Risk management for product-service system operation”, International Journal of Operations \& Production Management, Vol. 36 No. 6, pp. 665-686.

Reim, W., Sjödin, D. and Parida, V. (2018), "Mitigating adverse customer behaviour for product-service system provision: An agency theory perspective”, Industrial Marketing Management, Vol. 74, pp. 150-161.

Rifkin, J. (2000), The Age of Access: The New Culture of Hypercapitalism Where All of Life is a Paid for Experience, Penguin, New York.

Rogers, E.M. (1976), "New product adoption and diffusion”, Journal of Consumer Research, Vol. 2 No. 4, pp. 290-301.

Roth, A.V. and Menor, L.J. (2003), "Insights into service operations management: A research agenda", Production and Operations Management, Vol. 12 No. 2, pp. 145-164.

Roy, R. and Cheruvu, K.S. (2009), “A competitive framework for industrial product-service systems", International Journal of Internet Manufacturing and Services, Vol. 2 No. 1, pp. 4-29.

Rust, R.T. and Cooil, B. (1994), "Reliability measures for qualitative data: Theory and implications", Journal of Marketing Research, Vol. 31 No. 1, pp. 1-14.

Sakao, T., Rönnbäck, A.Ö. and Sandström, G.Ö. (2013), "Uncovering benefits and risks of integrated product service offerings_-Using a case of technology encapsulation”, Journal of Systems Science and Systems Engineering, Vol. 22 No. 4, pp. 421-439. 
Sampson, S. (2000), "Customer-supplier duality and bidirectional supply chains in service organizations", International Journal of Service Industry Management, Vol. 11 No. 4, pp. 348-364.

Sampson, S. and Froehle, C. (2006), "Foundations and implications of a proposed unified services theory", Production and Operations Management, Vol. 15 No. 2, pp. 329-343.

Sampson, S. and Spring, M. (2012), "Customer roles in service supply chains and opportunities for innovation”, Journal of Supply Chain Management, Vol. 48 No. 4, pp. 30-50.

Schepers, J., Falk, T., de Ruyter, K., de Jong, A. and Hammerschmidt, M. (2012), "Principles and principals: Do customer stewardship and agency control compete or complement when shaping frontline employee behavior?", Journal of Marketing, Vol. 76 No. 6, pp. 120.

Singh, J. and Sirdeshmukh, D. (2000), “Agency and trust mechanisms in consumer satisfaction and loyalty judgments", Journal of the Academy of Marketing Science, Vol. 28 No. 1, pp. $150-167$.

Smith, L., Maull, R. and Ng, I.C. (2014), "Servitization and operations management: A service dominant-logic approach", International Journal of Operations \& Production Management, Vol. 34 No. 2, pp. 242-269.

Smith, J., Nagy, P., Karwan, K. and Ramirez, E. (2012), “The contingent nature of service recovery system structures", International Journal of Operations \& Production Management, Vol. 32 No. 7, pp. 877-903.

Sousa, R. and Voss, C.A. (2008), "Contingency research in operations management practices", Journal of Operations Management, Vol. 26 No. 6, pp. 697-713.

Steven, M. (2012), “Risk management of industrial product-service systems (IPS2)- How to consider risk and uncertainty over the IPS2 lifecycle?", Leveraging Technology for a Sustainable World, Springer, Berlin and Heidelberg, pp. 37-42. 
Strauss, A.L. and Corbin, J. (1998), Basics of Qualitative Research: Techniques and Procedures for Developing Grounded Theory, $2^{\text {nd }}$ ed., Sage Publications, Newbury Park, CA.

Tukker, A. (2004), "Eight types of product-service system: Eight ways to sustainability? Experiences from suspronet", Business Strategy and the Environment, Vol. 13 No. 4, pp. 246-260.

Tukker, A. and Tischner, U. (2006), "Product-service as a research field: Past, present and future. Reflection from a decade of research", Journal of Cleaner Production, Vol. 14 No. 17 , pp. $1552-1556$.

Ulaga, W. and Reinartz, W.J. (2011), "Hybrid offerings: How manufacturing firms combine goods and services successfully", Journal of Marketing, Vol. 75 No. 6, pp. 5-23.

Victorino, L., Field, J., Buell, R., Dixon, M., Meyer Goldstein, S., Menor, L., Pullman, M., Roth, A., Secchi, E. and Zhang, J. (2018), “Service operations: What have we learned?", Journal of Service Management, Vol. 29 No. 1, pp. 39-54.

Yin, R.K. (2017), Case Study Research and Applications: Design and Methods, Sage, London.

Wirtz, J., So, K., Mody, M., Liu, S., and Chun, H. (2019), "Platforms in the peer-to-peer economy", Journal of Service Management, Vol. 30, No. 4, pp. 452-483.

Zomerdijk, L.G. and de Vries, J. (2007), "Structuring front office and back office work in service delivery systems", International Journal of Operations \& Production Management, Vol. 27 No. 1, pp. 108-131. 